\title{
Staying close by moving out. The contextual meanings of personal autonomy in the life stories of women of Moroccan descent in The Netherlands
}

\author{
Marjo W. Buitelaar
}

Published online: 3 April 2007

(C) Springer Science + Business Media B.V. 2007

\begin{abstract}
This article focuses on the themes of personal autonomy and communion in the life stories of highly educated women of Moroccan descent in The Netherlands. It is argued that the task to make the most of what The Netherlands have to offer whilst staying loyal to parents who have paved the road, creates a double bind which is the motor behind the development of the 'plot' of all collected life stories. While the interviewees tend to interpret the dilemmas they face in finding a satisfactory balance between autonomy and communion in terms of differences between 'the Dutch individualistic society' and 'the collectivistic values' which characterize 'the Moroccan' or 'Islamic culture,' comparison with the life stories of members from the established Dutch working class who have socially moved upward, demonstrates that the dilemmas faced are similar. In many instances, climbing up the social ladder appears to play a bigger role than ethnic or religious background in ambivalent feelings abouth belonging. Where the life stories of migrant daughters differ is in narrations on the inheritance of loss and aspirations intrinsic to migration. Also, Moroccan colours, smells, objects, symbols and patterns of conduct inform the interviewees' sense of belonging and supply them with powerful images and words to describe their experiences.
\end{abstract}

Keywords Life history · Upward mobility · Gender · Muslims in Diaspora · Narrative identity · Migration

They left their future behind to give us a better future(Rahma Er-Riffi) ${ }^{1}$

\footnotetext{
${ }^{1}$ Like all other names used in this article, Rahma Er-Riffi is a pseudonym used to protect the privacy of the interviewee.
}

M. W. Buitelaar $(\bowtie)$

Faculty of Religious Studies \& Theology, University of Groningen,

Oude Boteringestraat 38, 9712 GK Groningen, The Netherlands

e-mail: m.w.buitelaar@rug.nl 


\section{A polivocal biography}

The opening quote to this article was stated by a Dutch woman of Moroccan descent, as she spoke about the endeavours of her parents to create better lives for their family by migrating to The Netherlands. Rahma is one of the women who were willing to tell me their life stories for my research project on young women of Moroccan descent who have university degrees and/or hold positions in which such qualifications are required. The aim of this research is to gain insight into the ways the legacy of migration features in the life stories of women who were either born in The Netherlands, or came to live there before the age of ten. The research focus is on the ways the interviewees construct a concept of self out of their shifting, multiple social identifications in what McAdams (1993: 266) would call their 'personal myths:' the continuously revised biographical narratives of those behaviours and episodes in life that form answers to the question 'Who am I?'(cf. van Langenhove and Harré 1993: 82). I am more particularly interested in the intersection of ethnic, religious, class and gender identifications.

Rather than proposing specific topics, the metaphor of the life-story as a book containing different 'life-chapters,' 'characters' and 'story-lines' was used to invite the interviewees to produce self-narratives. In this way, they were free to select the topics that they judged to be of interest. ${ }^{2}$ Each life-story interview consisted of two to three sessions of $2-3 \mathrm{~h}$. In total, 28 women were interviewed. ${ }^{3}$

A recurrent theme in life-stories is seeking a satisfactory balance between personal autonomy and communion (cf. McAdams 1993). Autonomy concerns the desire for independence and self-realization. It is expressed in narrations about efforts to control one's own life and to distinguish oneself from others. Communion refers to attempts to transcend one's individuality and merge with others in strong, intimate, and loving relationships.

In this article I will analyse how narrations referring to autonomy and communion produced by the interviewees relate to ethnic, religious, gender and class identifications. I do so by using the concept of the 'dialogical self.' According to this theory of identity, the self is dialogically constructed because people take into account the perspectives of others in their sense of self. Thus viewed, personal identity is the temporary outcome of our responses to the various ways in which we are addressed on the basis of our positions in the power relations in and between the different social and cultural fields in which we participate (Hermans 2001). The interviewees' ethnic identity, for example, is informed by the ways in they are addressed 'as Moroccans' in different contexts. The messages conveyed by their

\footnotetext{
${ }^{2}$ Since narratives are always shaped by the audiences that each participant in the interview situation has in mind, to a large extent this 'freedom' was, of course, illusory (cf. Olson and Shopes 1991: 193). For one thing, the responses of the interviewees were influenced by the fact that I had contacted them because of their Moroccan background. Also, exactly because Islam has become such a dominant identity-marker in The Netherlands, much of what the interviewees told me was organized around the purpose to challenge assumed misconceptions of presumed readers. Either tacitly or explicitly, then, the women who participated in the project had their own agenda when agreeing to cooperate (cf. Berger Gluck 1991).

${ }^{3}$ For three of the interviewees, going through the whole interview format proved to be too time-consuming or confronting, so that the interview was aborted after concluding an overview of their 'life chapters' in the first or second session.
}

Springer 
parents, relatives in Morocco and Dutch friends about what it means that they are Moroccan vary. While parents may claim sameness by referring to Moroccan identity, Dutch people and Moroccans in Morocco may claim difference, albeit in different ways. Such discursive 'selfings and otherings' (cf. Baumann and Gingrich 2004) are embedded in existing powerrelations which may beconfirm or contested.

In variation to Mead's concept of the 'generalized other,' Hermans emphasises the importance of 'collective voices' in the construction of identity. In narratives about intersecting identifications, we cannot but make use of the ways in which the meaning of words is embedded in field-specific repertoires of practices, social capital, characters and discourses that characterize the various modalities of the identity-categories through which we are constituted. All words have the 'taste' of a specific profession, for example, or a specific genre or generation, et cetera. (Bakhtin 1981: 293-294). When we speak, we actively co-construct these collective voices. By applying words to our own specific contexts, we intone them and place them in relation to other words, thus reshaping them as we use them (Shotter and Billig 1998: 24).

There are, however, restrictions on the freedom to improvise upon discourses and add new flavours to the already existing 'taste of words.' If our self-representations are to be understood by others, they must be oriented towards the specific conceptual horizon of our listeners. In turn, their anticipated 'answers' are significant to our experience of the self (Bakhtin 1981: 280). Identity is therefore dialogically constructed in both listening to discourses and using them to construct one's own narratives. Some voices that address the 'dialogical self' are more penetrating than others. Our social positions, for instance, create dispositions to voice opinions or to silence oneself, to enter into activities or to refrain from doing so (Holland et al. 1998: 136).

The concept of the dialogical provides tools to analyse how individuals speak from different I-positions within the self, switching between various collective voices and sometimes mixing them as they take different positions. It also draws attention to the ways in which different collective voices may or may not conflict, and to contextual factors which contribute to one or several voices becoming more dominant or organizing than others in self-narratives.

Since people always belong to several groups and categories at the same time, they construct a series of alternative and often inconsistent self-representations. These self-representations are based on different chains of selected personal memories and may be organized in terms of quite different cultural schemata (Ewing 1990: 253). Depending on the actual or imagined positions from which selfnarrations are told, people tell different stories about their past, present and future. Through self-reflection and telling, a person is able to bring different experiences and views together in a composite whole. Some parts become more influential than others, and as the self shifts between I-positions, emotions are organized differently. Also, the basic narrative themes of agency and communion may receive differential attention in stories told from different I-positions (cf. Hermans and Hermans-Jansen 2001: 128). ${ }^{4}$

\footnotetext{
${ }^{4}$ Thus, life stories may change as circumstances change.
} 
One strategy to create a sense of wholeness in the face of these multiple selfrepresentations is to construct a self-narrative in which they are integrated. If our life-story is to make sense, it should cohere in ways appropriate to the standards made available to a person of our identity in the groups in which we participate (Appiah 2005: 22). Life-stories are therefore highly informative about the organization of intersecting identifications. Narratives about key events such as high, low and turning points in particular are pre-eminent dialogical moments in the construction of identity (cf. Josselson 1995: 42).

Putting together story lines that are informed by the 'voices' of different groups to which the interviewees belong requires quite some 'biographical work.' In nearly all life stories of women who spent their first 3 years of life in Morocco, much attention is paid to the transition from Morocco to The Netherlands. Narrations about Morocco often differ in tone from those set in The Netherlands. The impact of migration on the interviewees as young girls tends to be expressed by describing the two countries in terms of oppositions. When Rahma, for instance, recalls her family life in Morocco, she describes a harsh and uncertain life of a family struck with great poverty. Stories about her first impressions of the house where she and her family were to live in The Netherlands call forth a very different image:

We went in and, well, you know what children are like: we raced up and down the stairs and checked out all rooms. One of us would shout: 'Blimey, there's a televisionset in the living room!' I don't think we noticed that it was a very old one. Somebody else went crazy over the sofa. And I ran into the shower. I will never forget how it felt to discover that it produced hot water! Also, there turned out to be a bed for every single one of us. We just could not believe it!

Rahma loves recalling memories about her first years in The Netherlands. Her favourite family story relates how her father, preparing for the arrival of his family, painted the whole house in 1 night. Having inhaled too much of the gas which eminated from the freshly painted rooms, he had not been able to sleep that night.

Rahma concludes her narrations about her arrival in The Netherlands with the following epilogue: 'When I realize, all those things that my parents did for us... They left their future in Morocco behind to give us a better future in The Netherlands.' This epilogue points to a twofold message behind the stories about the endeavours of Rahma's parents: first of all that Rahma owes it to them to make the most of her life in The Netherlands, and secondly that she should never forget who made all this possible for her. Indirectly, the epilogue is a statement about paradoxical expectations concerning her strive for personal autonomy and communion.

What people who differ in class, gender, age and cultural contexts experience as a satisfactory balance between autonomy and communion in their own lives can vary widely. The extent to which personal autonomy and self-realization are valued in the West since modernity is exceptional. In many cultures socialisation is aimed at developing a stronger collective identity than an individual identity (cf. Camilleri and Malewska-Peyre 1997).

Also, it seems to be a universal trend that men seek more strongly to attain autonomy while women focus more communion. Once they attain middle age, however, western men tend to become less achievement-oriented and value stable 
personal relationships more highly. Such patterns illustrate that the 'choices' people make over their life course in developing identifications dominated by either autonomy or communion are less voluntary or noncommittal than some postmodern theorists on identity would like us to believe (see also Bhabha 1994).

Living in a multicultural society allows people to draw from different cultural resources belonging to the various groups to which they belong. Since narrative identity is always developed through dialogues with others, the social contexts within which they do so and the 'speech genres' through which they have learned to express themselves form the matrices that define the possibilities and margins to do so.

In what follows I will analyse how the interviewed highly educated women of Moroccan descent create a balance between narrations of autonomy and communion in their life stories and how they use the various cultural repertoires that they have at their disposal in doing so.

\section{School and career planning against the background of migration}

Within the context of my research, 'highly educated' refers to women who have a university degree and/or hold positions in which such qualifications are required. ${ }^{5}$ Considering this selection of women it should come as no surprise that autonomy features prominently in their life stories. A narrative style expressing how things merely 'happened' to the storyteller or in which narrations on relationships predominated over achievements is rare. Dominant in most life stories are narrations about the strategies the interviewees employed to obtain a place of their own in Dutch society.

Characteristic for the emphasis on independence and achievements in the stories, is that 14 of the 25 women who completed the whole interview mentioned obtaining a degree or high marks when asked about a peak-experience in their lives. Fouzia for instance, did not have to think at all when asked about a peak-experience: 'Obtaining my degrees! It proved both to myself and to others that I have a lot to offer.' The wish to 'prove' oneself is a common theme in many of the collected life stories, particularly in narrations on peak-experiences referring to agency. Paying off debts to parents who relinquished 'their future' in Morocco in order to provide their children a better future in The Netherlands is a recurrent motive.

Reported peak-experiences not directly linked to autonomy, usually concern friendships, marriage or the birth of a child. In nearly all cases, however, such peak experiences were interpreted as a turning point in the life of the interviewee, in the sense of her having reached a point where she had freed herself from a compulsive

\footnotetext{
${ }^{5}$ One of the reasons why the first phase of this life-story project was restricted to this category of women is that processes of continuity and change will probably stand out most clearly in the study of "extreme cases' (cf. Glaser and Strauss 1967). In this initial phase, the focus on higher educated people is also helpful since they have been trained to be reflexive and articulate. Also, the 'successful women' who are portrayed in the study can function as role-models for young girls of Moroccan descent, while correcting the image that many Dutch people tend to have of Muslim women as uneducated, oppressed creatures with no will of their own.
} 
urge to outperform others. Rather than formulating their (former) obsession with achievements in terms of personal wishes, most women explained their former behaviour as motivated by the wish to comply with the high expectations of relatives or the wish to defy low expectations of others.

The importance of recognition for extraordinary achievements is a biographic theme that is not unique for highly educated women with a migration background (cf. Higginbothom and Weber 1992; Roberts and Rosenwald 2001). On the contrary, besides episodes referring to the specific family history of migration, the life stories show remarkable resemblances with the life stories of other categories of people who have experienced upward social mobility.

One difference with highly educated persons from the established western labour classes is that economic migrants are by definition motivated to move up the social ladder. Until the mid 1980s Mediterranean migrants in The Netherlands were called 'guestworkers' and both Dutch people and migrants themselves assumed that after a period of hard work and saving money they would return to their country of origin.

What migrant parents wanted for their children in terms of education reflected these expectations. Boys were encouraged to learn a trade which would allow them to earn a living in their home country: they were trained as car mechanics, plumbers, electricians et cetera. Similarly, sending their daughters to same sex domestic science schools was hoped to increase their value on the marriage market in comparison to girls who had stayed behind in Morocco.

Since then, the attitudes of Moroccan parents in The Netherlands have changed considerably. Many of them urge their children to obtain the highest degrees possible (cf. Hermans 2002). One reason for this is related to societal changes in the country of origin. A good education, both for boys and girls, is presently highly valued in (urban) Morocco. More importantly, most migrants in The Netherlands have given up the idea, at least tacitly, to return to Morocco and appear to accept that the future of their children will be in The Netherlands. The assumption that the highest education possible will enhance the chances of their children on the Dutch labour market makes many parents push their children to study at the highest educational levels (Ledoux 1996). Despite the negative reports on the achievements of migrant children in the media, research shows that the position of students of Moroccan descent has ameliorated considerably during the 1990s. When comparing their factual position with the expected results against the background of the educational level of their parents and the space that is available in their homes per person, their success equals that of Dutch children who share the same characteristics (Crul 2000, p. 18).

The number of successful children of Moroccan background is increasing rapidly. Particularly girls are catching up thanks to disappearing risk factors such as young marriages and traditional views on women's roles (Crul 2000, p. 158). To be sure, not all parents agree on the need for a good education for their daughters. Interestingly, ambitious girls who have to negotiate with reluctant parents refer to Islamic teachings and female Muslim rolemodels to convince their parents that Islam summons Muslims to educate themselves. They may point to Khadidja, for example, the first wife of the Prophet Muhammed, who is depicted in Islamic historiography as a rich and independent tradeswoman when she proposed to the Prophet, or his later and most favourite wife Aisha, who is known for speaking her mind to her Springer 
husband and for leading a battle after his death (cf. Bartels and De Koning 2007). It turns out that the presence of older sisters or aunts, who were the first in their families to obtain higher education, is an important factor in the chances for a successful school career of girls. Such 'pioneers' have paved the way for the generation that followed in their footsteps (Crul 2000, p. 158).

In the past decade, changes have occurred in Moroccan families in The Netherlands. The fact that most children are better educated than their parents leads to shifts in the power relations within families. In return, these changes have implications for the cultural repertoires of migrant families. Voices expressing values and modes of conduct that differ from what parents have been brought up with are getting stronger. Nearly all interviewees belong to the 'pioneers' who witnessed the first signs of these changes. Their life stories are populated with voices expressing the contradictions, dilemma's and ambivalences which are related to changing cultural patterns.

All women indicate that it was important to their parents that their daughters were educated, at the least to the level of elementary school. From their narrations it can be deduced, however, that most parents had little to no knowledge about the contents of their daughter's education, nor about the ways that schools are organised and operate. Boushra, for example, speaks about the misunderstanding that school activities such as parents evenings created at home. The little girl Boushra literally had to 'translate' between voices addressing her from her different I-positions:

I had to explain to my mother about parents' evenings. Of course I did not really know myself. My mom would say. 'Why do your father and I have to show up in school? Have you been up to something bad?' 'No, I haven't done anything. They only want...' 'You must have done something!' That's how things went. So it was to me, well, I had to explain to them that it was a standard procedure.

Boushra also had to act as an interpreter for her parents. At times she experienced this as a heavy burden:

At a certain stage you outpace your parents, particularly in terms of language. Within a few months my sisters and I got by fairly well in Dutch. But my parents didn't. They still don't, but at the time the difference was painfully large. So we had to go shopping, make inquiries for them, do their administration and all that. That's when the parent-child relation actually gets inverted.

Because of their roles as mediators between their parents and Dutch society, the interviewees had very big responsibilities at a very early age, something which many express having ambivalent feelings about. On the one hand this yielded them independence, power and freedom, but on the other hand women regret not having enjoyed a carefree childhood.

Amongst other things, because their parents' language problems and lack of knowledge about the Dutch school system, many women had to decide on and organise the transition from elementary school to high school themselves. The Dutch system has a range of four school programmes, ranging from lower occupational 
training to pre-university education. Some women were advised by a teacher or the parents of a Dutch classmate, but others had to take all decisions by themselves and handled the administrative aspects of admission on their own. Narrations about this often bespeak pride, but also loneliness and implicit or explicit frustrations about the helplessness of poorly or uneducated parents trying to support their daughters. A scornful laugh escaped Fatna, for example, when I asked her whether her parents encouraged her to study:

How could an illiterate mother encourage her daughter? But I see what you mean. That I should have a good education was very important to my mother. Not for the sake of education itself, though. To her it was only a means to an end. What counted for her was that a good education grants women independence; she did not want me to have to depend on others.

Voices encouraging the interviewees to work hard, get high marks and do better in life than their parents are abundant in the life stories. As is illustrated in Fatna's remark about her mother's attitude towards education, the stories only rarely contain descriptions of parents who show an interest in the contents of the education of their offspring. According to most women, like Fatna's mother, their parents only emphasized the importance of education as a means to become independent. Most interviewees express regrets about this parental lack of intrinsic interest. Talking about her parents Layla, for example, speaks in a tone that is not free of reproach:

At times I really missed that. Sometimes I'd say to myself: 'I am going to involve them, tell them about certain things that are important in my life.' But the truth is that my parents had no interest in that at all. I guess that's because my life is so different from what they know or can imagine. It isn't always easy for me. I sometimes think: 'Darn, you could at least ask me?!'

The interviewees explain the difficulties to talk with their parents about school and work experiences in terms of their living 'in two cultures,' usually understood in terms of the 'Moroccan/Muslim culture' and 'Dutch culture.' I agree that the experiences that the women talk about are related to differences between the various cultural contexts in which they participate. I would argue, however, that the biographical work that they face in finding a satisfactory balance between autonomy and communion, - while often cast in terms of finding a balance between Islamic and/or Moroccan values of collective identity and respect to one's parents on the one hand, and Dutch values of individuality on the other - in fact has less to do with ethnic or religious differences, but rather with class differences and the impact that migration has on family relations and expectations of self-realization.

While ignorance about the Dutch school system, for example, does explain the lack of interest of parents, this is related at least as much to the fact that they themselves have either enjoyed very little or no formal education as to their Moroccan background. Indeed, researchers have reported similar remarks about parental lack of intrinsic interest in the educational careers of their offspring from Dutch and other western persons from a lower class background who have moved up the social ladder (cf. Brands 1992; Higginbothom and Weber 1992).

Of course, migrant families suffer even more in terms of lack of the forms of economic, social and cultural capital prevailing in The Netherlands than families 
from established working classes. As a result of their migration and economic position, theirs is more strongly what Bourdieu (1984) refers to as 'a culture of necessity.' Having to make do with the little that they have, instrumental aspects of life have priority over expressive ones. In this context, hard work and outstanding performance is a way to compensate for the lack of contextually relevant forms of capital. Layla's father taught his daughter this explicitly:

My father used to say: 'If you want to be equal to Dutch people, that is, if you want them to accept you as an equal, you will have to do better than them, stand head and shoulders above them. Performing on the same level is not good enough. Then they will still feel superior to you.'

More than anything else, like autochthonous working class children, the interviewees were encouraged to strive for economic autonomy. Not surprisingly, an enormous if not compulsive urge to perform well is one of the central themes in most collected life stories, a characteristic that they share with the life stories of Dutch academics with a working class background (cf. Brands 1992).

One significant difference is that most interviewees in my research explained their drive to perform well in terms of a wish to stand up against the stigmatizing remarks and attititudes of Dutch people concerning Moroccans. Take Boushra, who stated: 'Time and again I had to say to myself: you are not inferior to them and you will prove that.' Another woman said she wanted to 'Work like hell' to give her classmates 'something to think about.'

All interviewees expressed a strong wish to join in with their Dutch classmates. While outperforming others may contribute one's sense of self-esteem, it does not automatically lead to acceptance by others as one of them. Therefore, besides narrations on outstanding performances most life stories also contain moving anecdotes documenting attempts to stand out as little as possible in other respects. Some women, like Zeineb, explicitly mention feelings of shame concerning their ethnic and religious background: 'Sometimes when my classmates would make disparaging remarks, about headscarves for example, I said to myself; Oh dear, I pray to God Almighty that my mother won't show up at school!'

Despite their efforts not to draw attention to themselves, many interviewees stood apart in class anyhow because most parents forbade their daughters to participate in certain school activities such as fieldtrips or school dances. Thus women felt it was 'drilled into them' as Boushra puts it, by both classmates and their parents, that they were different from Dutch children. In her description of her parents' views, Boushra quotes them in Moroccan-Arabic, thus emphasizing the gap between speech genres and expectations that characterized her life at home and at school:

When I asked: 'Why am I not allowed to go on a fieldtrip?' my parents would respond: 'Because you are Moroccan - Nti magrebiya.' That's how it got drilled into me that I am different [...] That hurt me a lot, particularly the pestering of my classmates. But also that I wasn't free to do as I liked because of the attitude of my parents. What I would say to myself to cope with that was - quite arrogant in a way - something like: 'They don't know any better.' That's how I could live with it without getting into a conflict with them. 
The picture emerging from the life stories is that the actual autonomy and power that the interviewees enjoyed at an early age because they were much more familiar with the Dutch language and society than their parents, contradicted with the hierarchical family structure and authoritarian style of upbringing to which their parents adhered, thus creating tensions. In the end, what nearly all parents wished first and foremost for their daughters was to become a wives and mothers.

Excusing the restrictive behaviour of her parents by saying to herself that 'They don't know any better' is a strategy which allowed Boushra to accommodate these contradictions in her relationship with her parents. In the quotation about the restrictions her parents imposed on her, we can see her switch between different I-positions: 'They don't know any better' is uttered by Boushra the highly educated and independent daughter. By calling this 'quite arrogant in a way' she shifts to another I-position. As the loving and respectful daughter, she excuses and denounces her own stance simultaneously. Boushra's self-criticism bespeaks a sense of guilt towards her parents for having outgrown them in certain ways.

\section{Staying close by moving out}

The task to make the most of one's life in The Netherlands, whilst remaining loyal to parents who made huge sacrifices by migrating to provide their children with a better life creates a paradox. Boushra mentioned two other strategies to cope with this 'double bind:' the first consists of calculating carefully which issues were worth negotiating about, and the second of 'soaking' matters before actually discussing them with parents:

What I really wanted was to have my driving license. So instead of making an issue of going to a school dance, I decided to nag them only over the permission to take driving lessons. That worked out fine, as long as I took it one step at the time. [...]. By the time high school drew to a close, I had set my mind on studying medicine. I had to deal with an admission quota, so that I had no idea in which university in The Netherlands I would be enrolled. When it turned out that I was accepted in a different university from the one in my home town, I decided to 'soak' the matter of moving out. For the first few years, I travelled back and forth. Next I started staying over at friends every now and then. As long as my parents knew these girls, they did not object. The following step was trying to convince them that it would be good for me to live on my own. Once my traineeship was about to start, I told them that I had no other choice than to move closer to the university. At that stage this was only a small step, and having grown accustomed to the idea of a daughter living elsewhere, they admitted just like that!

Like Boushra, most women reported episodes concerning negotiations or struggles between themselves and their parents over the issue of more freedom of movement (cf. Buitelaar 2002). Patience and diplomacy did not always work. One interviewee ran away from home twice as a teenager. Another one went through two suicide attempts in late adolescence. Several women told stories about feeling 
insecure about the chances of being able to stay in contact with their parents should they decide to leave home to live on their own.

Considering the motives for the need to perform well and the wish for independence that runs through most collected life stories, it may seem surprising that in general, most interviewees preferred to resign themselves and accomodate the restrictions imposed on them over running the risk of severing family ties. In order to be able to study without being disturbed, Esma, for instance secretly rented a room elsewhere in her hometown. During day time she enjoyed what she described as 'freedom,' but at night she returned home to act the obedient daughter. Another woman allowed her parents to marry her off to someone against her own wishes, while yet another decided to give up hopes for an academic career because her parents would not allow her to move to a university town.

Despite the frequent occurrence of painful episodes concerning sometimes quite drastic restrictions, nearly all life stories breathe the spirit of an enormous loyalty towards parents. Only in two cases were interviewees so resentful of one parent - in both cases a violent father - that they wished for no further contact. The unfailing loyalty of the other interviewees must partly be understood as a social legacy of migration. It is the proof of their gratitude towards parents who are depicted as having made substantial sacrifices in order to migrate to a country with much better opportunities for themselves and their children. I would argue, however, that there is more to this loyalty than gratitude. Fouzia's story about her first attempt to leave her parental home alludes to a second factor explaining the connectedness of migrant daughters to their parents:

My father said: 'If you walk out that door you will never have to come back again.' I packed my stuff and left the same night. I went through a very difficult time after that, because he would not allow any contact between me and the other family members either. And then Ramadan was approaching. I dreaded the prospect: how could I survive without my family? I had no idea how to get through that month. On my own? Impossible. So, eventually I decided to sell my house and go home.

Like Christmas for most people with a Christian background, for Moroccans and most other Muslims, the fasting month of Ramadan is a big family affair. Besides having important religious meanings, Ramadan also has connections with homey feelings. Such feelings are difficult to put into words but have a great appeal to people. The indefinable and often tacit desire or urge to recreate one's childhood home - even if that home environment has not only positive connotations illustrates the power of social-cultural legacies (cf. Salih 2003). By witnessing and participating in certain cultural practices, specific patterns of thought and action are literally incorporated into children. When a child learns to speak its mother tongue, for example, it both acquires a new use of its body which enjoins it to the collective identity and stories of its society, and it learns to 'think' according to the shared schemas and views of the group. It is predominantly on the basis of incorporated memories or 'embodied knowledge' that people develop what Bourdieu calls a 'habitus:' the active residue or sediment of past experiences which functions in the present to inform one's perceptions, thought and actions. One's habitus consists of 
dispositions, knowledge and competences incorporated throughout life which make one inclined, but not determined to act or think in typical ways (cf. Crossley 2001: 93).

Every one of us adapts the 'taste' of words voicing the cultural and social messages of the groups to which we belong to our own context of living. One's habitus is therefore always in flux. We are not the slaves of our habitus, but as Fouzia's decision to give up her independence and 'go home' illustrates, nor can we withdraw ourselves completely from habitual ways of acting and understanding. Changing habits or attitudes is not a matter of stripping off a piece of worn out clothing and putting on another. Even the radical option of a 'cultural exit' demands constant efforts to ignore the internalised voices one has come to reject. Silencing such voices permanently is an illusion; they are bound to speak up at unexpected moments.

The realization that all culture is embodied, illustrates the short-sightedness of the opinions voiced by people like the Dutch politician Ayaan Hirsi Ali, according to whom Muslim migrant women should discard all religious and cultural traditions in order to be emancipated. Without exception, all of the women interviewed in this research are very without having opted for a complete cultural exit. 'I could not do that,' Esma commented, when explaining why she, like Fouzia, returned to her parental home when released from the hospital where she had spent 3 months to recover from having been beaten up by her father for coming home late. Despite the fact that she describes the episode as the all time low in her life, she stated that it would have been 'self-denial' to break with her family:

It was very difficult to cope with what was happening without renouncing myself. I had to learn how to act from an inner force rather than respond to habits and expectations I was brought up with [...] It felt as though I might suffocate from all those expectations, but then again I did not have the power or guts to say: 'Get lost, I have nothing to do with your standards.' That's where you know that you depend on your family. It is the product of my upbringing that I am a group oriented person. [...] I am not an individual. Much as I have tried hard to be one, in the end I fear that I prosper most when I admit being a group person. I have decided that for me, life is much more agreeable that way.

Like Fouzia, Esma mentioned an additional reason for submitting to the harsh pedagogical regime of her parents. Similar to other categories of people who have moved upwardly socially, being the first person in her family to move up, she feels very responsible for her siblings (cf. Brands 1992; Higginbothom and Weber 1992): 'I was an example for those who came after me. My biggest fear has always been that because of my behaviour, my parents would impose even more restrictions on my sisters.' This sense of responsibility for other family members is a returning topic in the life stories.

That the daughters of Moroccan migrants tend to be very loyal to their parental milieu at the cost of sometimes substantial sacrifices, is often interpreted by Dutch people unfamiliar with their kind of situation, as proof that these women are not really emancipated. Anticipating such responses, some interviewees asked me not to 
use their stories about struggles with their parents in my publications in order to avoid 'feeding existent prejudices.' 6

The sad part about this situation is that the self-images depicted within the narratives tend to be interpreted by their parents, and other Moroccans of their parents' generation, as those of women who have, on the contrary, carried their emancipation too far. Fouzia's mother, for instance, reproached her daughter for having 'Dutchified' when the latter tried to share her ambitions in life with her mother. According to Fouzia, her mother: 'said something like: "Don't forget, a man will always be the umbrella of your existence"; or something to that effect. I thought to myself: ' $O$ my God, I just can't take any more of that kind of talk!'

Most life stories bear witness to the need the interviewees felt to prove themselves to different groups; to people of Dutch descent they felt like having to prove that 'as Moroccans' or 'as Muslims' they were neither 'backwards' nor 'oppressed,' whereas they had felt having to convince people of Moroccan descent that they are not 'bad women' who 'sell themselves out' and deny their Moroccan and Muslim roots. Layla addresses the issue of fighting 'at two fronts' explicitly:

What makes it really hard, is that one is fighting on two fronts. First of all I have to confront my own group, 'The Moroccans.' When they see me, they give me that critical look, you know. It's to them that I feel I have to excuse myself by saying: 'Listen, I'm not doing anything bad! Look at me, you should be proud of me, you can trust me.' All the time I had this feeling that I had to prove it time and again. It was as if I was saying: 'I may not behave exactly like you do, but I am still a Moroccan [...]. I respect and appreciate you, but I demand the same from you for myself.' Simultaneously, I felt I had to stand up for these same people in relation to the Dutch with their incessant, priggish questions and objections. They managed to knock me down with very subtle remarks about Moroccans. Although they were not talking about me personally, it affected me nonetheless when people talked like that about migrants.

\section{The 'dialogical self:' Dealing with different expectations}

That certain remarks 'affect' Layla even if they do not concern her person, illustrates the dialogical character of identity-formation. The different collective voices that address her, are different in tone and sometimes contain contradicting messages. It isn't easy for women like Layla to integrate the various storylines developed in her dialogues with members of the various groups in which she participates into one, coherent story.

Layla's response illustrates that dialogically constructing one's identity is not restricted to responding to the words and messages that are directly addressed to oneself. It also concerns inner dialogues between the collective and personal voices

\footnotetext{
${ }^{6}$ I have, of course respected this wish. References in this article to (violent) conflicts between daughters
} and parents are based solely on the narratives of women who did not object to my use of their stories. 
that one has internalized over the years. A particularly clear illustration of such inner dialogues comes to the fore in Boushra's pondering over the question why as a grown up person who is free to make her own choices, she still refrains from doing certain things which her parents had forbidden her as a child:

Take, for example, the case of a nice coat that I came across in a shop. I looked at it, liked it, but then I said to myself: 'Actually it's too short' [...] It would have been different had I thought: 'I don't like the colour' rather than 'It's too short.' Too short for whom or for what? This is the kind of situation in which I realize: 'Wait a minute! This is very schizophrenic conversation I am having with myself. Things like that happen to me time and again and it bothers me a lot. I am no longer part of that kind of family, I am entitled to decide for myself now. But somehow I can't seem to manage to get rid of this kind of thinking.

Boushra's inner dialogue illustrates that the various societal contexts in which we participate all have their own repertoires of 'characters' that are endowed with specific speech genres and patterns of behaviour, amongst which, as in this case, dress codes. In constructing our identity we cannot but make use of the meanings of words (or clothes!) within the contexts in which they were articulated. Each word 'tastes' of the contexts in which it has lived its socially charged life. The words we use are 'populated' with the intentions of others and they are set within the power relations between those whose intentions they bespeak (Bakhtin 1981, p. 293). Therefore, the influence of certain cultural expectations can be big, as Nadia also remarked:

When I still lived with my parents, when guests would arrive, I was expected to get up from whatever I was doing to serve them tea and act charmingly. [...]I'd go to the kitchen to do the dishes and clean up, making a point of doing very well, because what if those people would conclude that I wasn't a good daughter?! The crazy thing was: I even wanted to be what was considered a good daughter in that setting! I had internalized that wish to the extent that it was very difficult for me to realize that deep down I didn't feel like doing these things at all.

\section{Familiar tastes and new flavours}

In comments such as 'the crazy thing was' and 'it was difficult for me to realize' Nadia the independent successful adult woman enters into a dialogue with Nadia the teenage daughter. This illustrates that life stories are told backwards: from their present position, the narrators look back to give a retrospective account for who and where they presently are, often commenting on the child/young adult that they are describing. Such comments are dialogical moments par excellence which tell us a lot about the efforts of the narrator to pull together different story lines.

Something similar happens in the quoted excerpt from the interview with Layla where she speaks of 'fighting at two fronts.' When she begins this narration, she first speaks in the present tense, to switch to the past tense a few lines later. The 
switching of tenses expresses that Layla the narrator has distanced herself from the younger Layla, who in her twenties wore herself out by continually trying to defend herself. Later in the interview she states explicitly that she no longer feels the need to explain herself to others. Apparently, she has managed to ignore some of her contradictory inner voices.

The ways in which Nadia and Layla combine different perspectives in their narratives demonstrate that each speaker of a language is capable of adding new flavours to the 'tastes' of the words they use by adapting them to their own specific context and putting their own emphases. To appropriate language and submit it to one's own intentions and accents is, however, a difficult and complicated process. The meanings of words and practices change only very slowly (Bakhtin 1981: 294). In the collected life stories, this comes to the fore most clearly in narratives concerning partner choice.

While most interviewees tell their stories about school choices and career planning in an assertive tone, they tend to speak more hesitantly about their (wished for) love relations and partner choice. Narratives about this dimension of life illustrates as no other the ambivalence that accompanies social cultural changes. Words like 'actually/ideally,' 'yet,' 'on the one hand-on the other' occur much more frequently in accounts regarding partner choice than in any other story. Without exception, all women state that they ('actually/ideally') prefer a husband of Moroccan descent ('yet') raised in The Netherlands and who ('on the one hand') does not renounce his roots but ('on the other hand') should not be narrow minded either. Religious considerations, the approval of parents and the wish for cultural continuity are the main reasons forwarded to explain this. Nadia summarizes her wishes as follows:

However much I may have 'Dutchified,' would I want a husband who has no clear picture about typical Moroccan issues and who would need so much socialization and so many explanations [...]. No, actually I wouldn't!'

Describing preferences by stating what one does not want, as Nadia is doing here, indicates that the words and characters that match what one does wish for are rare in the cultural repertoires that inform one's frames of reference. Indeed, most interviewees pointed out that the kind of partner that appeals to them is rather uncommon. Many life stories contain anecdotes about the experiences of friends, relatives or the narrator herself who fell flat on the face when boyfriends of Moroccan descent who seemed to be open-minded at first, later turned out to entertain traditional sexist views on gender relations. Because of such (stories about) bad experiences, many women reported having grown suspicious or sceptical about Moroccan men. Esma, for example, stated cynically: 'They begin with promising you all the stars in the sky, but they end up closing the curtains.'

Esma herself was lucky. Her boyfriend did very well on the tests she put him through to check his degree of male-chauvinism. The couple are now happily married, as are 12 other interviewees. The other 15 women did not have a partner at the time of the interview. Considering their ages - all of them were between 25 and 40 years old - this is a large number of singles. Two single women stated that they did not want a partner. Others did not rule out entering into a relationship, but said 
they were hesitant to do so because they feared losing their freedom. Again other singles, like Nadia, remarked that the problem was not their own fear, but that of men who shrink away from strong women:

I guess I am a bit tough. Maybe - that's what people tell me - I scare men off. I don't hesitate to tell them when I don't like something or when a particular conversation does not interest me.

Statements like 'I am a bit tough,' or 'I am egoistic,' or the even more negative 'I am an ogress,' occur in many of the collected life stories. These self-evaluations concerning autonomy have a negative 'taste' to them. They point to the ambivalent self-images which the interviewees entertain as a result of their belonging to various intersecting cultural contexts. The high degree of autonomy that these women enjoy is inconsistent with positive representations of female characters in traditional Moroccan cultural repertoires. Therefore, the words that the interviewees choose to describe certain personal traits which they are proud of 'on the one hand,' are not free from negative connotations 'on the other.' As a result, there is a tension in certain aspects of their self-image that leaves them searching for words, much like many of them are still searching for suitable partners.

This biographical task of reconciling different dimensions of one's self-image is, of course, not unique for highly educated daughters of Moroccan migrants. In general women tend to have more difficulties in reconciling agentic and communal self-representations than men do (cf. Lieblich et al. 1998). Also, it appears to be a worldwide problem for higly educated women to find a suitable partner, as the documentary Fatal Reaction on single women in Bombay, Moscow, New York and Singapore illustrates (Cinemien: 1996-1998). Furthermore, the fact that the interviewees belong to the small category of 'pioneers' from migrant communities to move upwards socially, reduces their chances to meet male soul mates (cf. Hooghiemstra 2003, p. 49). In the meantime, an increasing number of daughters and sons of migrants enter Dutch universities. Moroccan and Muslim students' unions and internet sites like Maroc. NL have become important meeting places for these young adults. For the younger siblings and nieces of the women interviewed, it will probably be easier both to find a suitable partner and to formulate more positive feminine self-evolutions.

\section{Concluding remarks: The contextual meanings of biographic choices}

Analysis of the ways in which the themes autonomy and communion feature in the life stories of highly educated women of Moroccan descent in The Netherlands illustrates that the construction of identity is a matter of careful orchestration of the various collective and individual voices that address us and through which we speak as we respond to the numerous, sometimes contradictory messages we receive by participating in multiple social and cultural contexts. Therefore, personal autonomy can never be absolute; it is always relational. In the case of the life stories discussed, this means that the biographical 'choices' the interviewees have made regarding personal autonomy and communion should be understood first and foremost against their migration background. The message to make the most of the opportunities that 
The Netherlands have to offer whilst staying loyal to parents who have paved the road, creates a double bind which is the motor behind the development of the 'plot' of all collected life stories.

Besides personal traits, which obviously have their role to play in the narrated endeavours to attain personal autonomy, the interviewees' wish to express their gratitude and loyalty by realizing the economic aspirations of their parents appears as an important motive. I would furthermore argue that their desire for personal autonomy is related to yet another legacy of migration. Lacking the social and cultural forms of capital which prevail in the networks that they have become part of, and confronted with prejudices concerning Muslims in general and Moroccans in particular, these Moroccan pioneers in upward mobility have to struggle hard to succeed in their new situations. Narrations on outperforming classmates and colleagues refer to coping strategies that the interviewees have developed to do so.

Internalizing the voices which address them in the Dutch social and cultural contexts in which they participate, these women have developed wishes for selfrealization which are new in their families. Therefore, they face the biographical task of finding a satisfactory balance between the acquired need for personal autonomy on the one hand, and the loyalty and connectedness to a parental milieu which is characterized by family values and a hierarchal family structure which allows for less freedom of movement than the women wish for themselves on the other.

For every chosen solution to tackle biographic assignments, a price must be paid. For the migrant daughters interviewed, while their responsibilities for both their own choices and those of other family members provided them with considerable freedom and power at a very early age, these responsibilities were also a heavy burden and precluded a careless childhood. For most, the need to outperform others was another source of constant worry. Also, because of their upward mobility and entry into societal groups which were new to them and where, as yet, they are still exceptional, the issue of where they belong became a pressing matter. Like members of the established Dutch working class who have moved upward, it is difficult for the interviewees to shake off the feeling that they will always remain outsiders in their class or office because no matter how hard they try, they will never succeed completely in adopting the speech genres, dresscodes and other aspects of the prevailing cultural repertoires.

To a considerable extent, however, they have also incorporated the collective voices belonging to these cultural repertoires, so that they become ambivalent about their appreciation for the old familiar 'tastes' of the words from their mothertongue. As a result, shifts occur in their world view and self-image and, willingly or unwillingly, they slowly detach themselves from their parental milieu. As the often elaborate narrations on the difficulties to find a suitable partner show, the price that these women might have to pay for their hard-won independence is to run the risk of becoming 'loners.'

This invites us to look at their narratives on personal accomplishments and autonomy from another angle. The role of life stories in the construction of identity is to provide convincing accounts for who we are and where we are presently. The numerous narrations on personal autonomy in the life stories of the interviewees may therefore also be read as stories which aid them to cope with and give meaning to both articulated and indefinable feelings of not belonging. 
The interviewees tend to interpret the dilemmas that they face in finding a satisfactory balance between autonomy and communion in terms of differences between 'the Dutch individualistic society' and 'the collectivistic values' which characterize 'the Moroccan' or 'Islamic culture.' It is often mentioned, for example, that respect and loyalty to one's parents is an important Islamic regulation. While recognizing this, from an anthropological point of view such culturalist explanations are unsatisfactory. Rather than focusing on cultural differences, anthropologists study cultural repertoires as the sites where social contestations take place. Comparison between the life stories of highly educated women of Moroccan descent in The Netherlands and members of the established Dutch working class who have socially moved upward, shows that the dilemmas persons from both categories face are not essentially different, even though the images and words they use to describe the similar social processes that they are involved in may vary.

What their stories share, for instance, are narratives about regrets and disappointment concerning parents who have very little knowledge about their children's life outside the family and do not show much interest. Also shared are feelings of loneliness and insecurity for having outgrown the parental milieu while never really managing to feel at home in the networks of their schoolmates or colleagues. Furthermore, both the highly educated daughters of Moroccan origin and members from the established Dutch working class who have climbed up the social ladder report feelings of unease or shame about the parental milieu in relation to classmates or colleagues, feelings that are paired with a sense of guilt towards their parents for having them. While coming from different cultural backgrounds, they also share an enormous sense of responsibility towards less successful family members. In short, in many instances, climbing up the social ladder appears to play a bigger role than ethnic or religious background in ambivalent feelings about belonging.

Where the life stories analysed here differ from those told by members of the established Dutch working class is in narratives on the inheritance of loss and aspirations. While on the one hand migrant parents appear to encourage their children more strongly to move up the social ladder, on the other hand they also impose more restrictions on their daughters than established working class parents tend to do.

The wish to climb up the social ladder is, of course, characteristic of economic migrants, regardless their ethnic or religious identity. Likewise, the strong social control over women is a feature that characterizes migrant communities in general (cf. Espín 1999; Lutz 1991), although the life stories show that Moroccan-Islamic tradition of sex-segregation influences the experiences of the interviewees as well (cf. Buitelaar 2002, 2006). Therefore, social class and the migration context are important factors shaping the endeavours of the interviewees to interweave the different story lines in their self narratives. Rather than 'Moroccan culture' or 'Islam,' these factors account for many of the dilemmas and tensions in their life stories.

Undeniably, however, being of Moroccan and Muslim origin plays and important role in the self narratives on autonomy and communion. Moroccan colours, smells, objects, symbols and patterns of conduct inform the interviewees' sense of belonging and supply them with powerful images and words to describe their experiences. As 
self-descriptions of agentic needs in terms of having 'Dutchified' illustrate, the fact that these women are addressed as Moroccans and Muslims both by members of Moroccan and Muslim communities and by members of the wider Dutch society likewise influences their narratives on personal autonomy and communion. This is not the same thing, however, as saying that there is anything intrinsically or exclusively Moroccan or Islamic in the ways women of Moroccan descent in The Netherlands seek a balance between personal autonomy and communion in their life stories.

\section{References}

Appiah, K. (2005). The ethics of identity. Princeton, NJ: Princeton University Press.

Bakhtin, M. (1981). The dialogic imagination. Four essays by M. M. Bakhtin. In M. Holquist (Ed.), Trans. C. Emerson \& M. Holquist. Austin: University of Texas Press.

Bartels, E., \& De Koning, M. (2007). Typisch Hollandse moslimmeiden in een Goudse minaret. In M. Buitelaar (Ed.), Uit en thuis in Marokko. Antropologische schetsen (pp. 133-145). Amsterdam: Bulaaq.

Baumann, G., \& Gingrich, A. (2004). Grammars of identity/alterity. A structural approach. New York: Berghahn.

Berger Gluck, S. (1991). Advocacy oral history: Palestinian women in resistance. In S. Berger Gluck \& D. Patai (Eds.), Women's words. The feminist practice of oral history (pp. 205-219). London: Routledge.

Bhabha, H. (1994). Between identities. In R. Benmayor \& A. Skotnes (Eds.), Migration and identity. International yearbook of oral history and life stories III (pp. 183-199). Oxford: Oxford University Press.

Bourdieu, P. (1984). Distinction: A social critique of the judgement of taste. London: Routledge.

Brands, J. (1992). 'Die hoeft nooit meer wat te leren.' Levensverhalen van academici met laaggeschoolde ouders. Nijmegen: Sun.

Buitelaar, M. (2002). Negotiating the rules of chaste behaviour. Re-interpretations of the symbolic complex of virginity by young women of Moroccan descent in The Netherlands. Ethnic and Racial Studies, 25(3), 462-489.

Buitelaar, M. (2006). 'I am the ultimate challenge.' Articulations of intersectionality in the life story of a well-known daughter of Moroccan migrant workers in The Netherlands. Special Issue on Intersectionality, A. Phoenix \& P. Pattynama (Eds.). European Journal of Women's Studies, 13(3), 259-276.

Camilleri, C., \& Malewska-Peyre, P. (1997). Socialization and identity strategies. In J. W. Berry, P. R. Dasen, \& T. S. Waraswathi (Eds.), Handbook of cross-cultural psychology, Vol. 2. Basic processes and human development (pp. 41-67). Boston: Allyn \& Bacon.

Crossley, N. (2001). The social body. habit, identity and desire. London: Sage.

Crul, M. (2000). De sleutel tot succes. Over hulp, keuzes en kansen in de schoolloopbanen van Turkse en Marokkaanse jongeren van de tweede generatie. Amsterdam: Het Spinhuis.

Espín, O. (1999). Women crossing boundaries. A psychology of immigration and transformations of sexuality. London: Routledge.

Ewing, K. (1990). The illusion of wholeness: Culture, self, and the experience of inconsistency. Ethos, $18(1), 251-278$.

Glaser, B., \& Strauss, A. (1967). The discovery of grounded theory. Chicago: Aldine.

Hermans, H. (2001). Conceptions of self and identity: Toward a dialogical view. International Journal of Education and Religion, 2(1), 43-62.

Hermans, H., \& Hermans-Jansen, E. (2001). Affective processes in a multivoiced self. In H. Bosma \& E. Kunnen (Eds.), Identity and emotion. Development through self-organization (pp. 120-140). Cambridge: Cambridge University Press.

Hermans, P. (2002). Opvoeden in een 'multiculturele' samenleving: Opvattingen, idealen, praktijken en problemen van Marokkaanse ouders. In C. Timmerman, P. Hermans, \& J. Hoornaert (Eds.), Allochtone jongeren in het onderwijs. Een multidisciplinair perspectief (pp. 95-148). Leuven/ Apeldoorn: Garant. 
Higginbothom, E., \& Weber, L. (1992). Moving up with kin and community. Gender \& Society, 6(3), 416-440.

Holland, D., Lachicotte, W., Jr., Skinner, D., \& Cain, C. (1998). Identity and agency in cultural worlds. Cambridge, MA: Harvard University Press.

Hooghiemstra, E. (2003). Trouwen over de grens. Achtergronden van partnerkeuze van Turken en Marokkanen in Nederland, Sociaal en Cultureel Planbureau, Den Haag.

Josselson, R. (1995). Imagining the real: Empathy, narrative and the dialogic self. In R. Josselson \& A. Lieblich (Eds.), Interpreting experience. The narrative study of lives 3 (pp. 27-44). Thousand Oaks, CA: Sage.

Ledoux, G. (1996). De invloed van 'sociaal milieu' bij Turkse, Marokkaanse en Nederlandse sociale stijgers. Sociologische Gids, 43(2), 114-131.

Lieblich, A., Tuval-Mashiach, R., \& Zilber, T. (1998). Narrative research: Reading, analysis and interpretation. Newbury Park, CA: Sage.

Lutz, H. (1991). Migrant women of 'Islamic background'. Images and Self-images. MERA Occasional Papers 11. Amsterdam: MERA.

McAdams, D. (1993). The stories we live by. Personal myths and the making of the self. New York: William Morrow.

Olson, K., \& Shopes, L. (1991). Crossing boundaries, building bridges: Doing oral history among working-class women and men. In S. Berger Gluck \& D. Patai (Eds.), Women's words. The feminist practice of oral history (pp. 189-204). London: Routledge.

Roberts, J. S., \& Rosenwald, G. C. (2001). Ever upward and no turning back: Social mobility and identity formation among first-generation college students. In D. P. McAdams, R. Josselson, \& A. Lieblich (Eds.), Turns in the road: Narrative studies of lives in transition (pp. 91-120). Washington, DC: American Psychological Association.

Salih, R. (2003). Gender in transnationalism: Home, longing and belonging among moroccan migrant women. London: Routledge.

Shotter, J., \& Billig, M. (1998). A Bakhtinian psychology: From out of the heads of individuals and into the dialogues between them. In M. Mayerfeld Bell \& M. Gardiner (Eds.), Bakhtin and the human sciences (pp. 13-29). London: Sage.

van Langenhove, L., \& Harré, R. (1993). Positioning and autobiography: Telling your life. In N. Coupland \& J. F. Nussbaum (Eds.), Discourse and lifespan identity, Language and Language Behaviors 4 (pp. 81-99). Newbury Park, London: Sage. 